\title{
Updating the landscape of direct-to-consumer pharmacogenomic testing
}

\section{Kelly K Filipski \\ John D Murphy \\ Kathy J Helzlsouer}

Epidemiology and Genomics Research Program, Division of Cancer Control and Population Sciences, National Cancer Institute, Rockville, MD, USA
Correspondence: Kelly K Filipski Epidemiology and Genomics Research Program, Division of Cancer Control and Population Sciences, National Cancer Institute, 9609 Medical Center Dr, Room 4E228, Rockville, MD 20850, USA

Tel + I 240276684 I

Fax +I 2402767920

Email Kelly.Filipski@nih.gov
This article was published in the following Dove Press journal:

Pharmacogenomics and Personalized Medicine

22 August 2017

Number of times this article has been viewed

Abstract: Pharmacogenomics has identified important drug-gene interactions that affect the safety and efficacy of medications. Direct-to-consumer genetic testing, when first introduced, included some pharmacogenomic-related genes. The current landscape of pharmacogenomic direct-to-consumer testing is reviewed. Prior published reviews of the literature were updated through February 2017 and a scan of the current availability of direct-to-consumer genomic testing by companies was conducted. Results of the review demonstrate a shift toward physicianapproved ordering.

Keywords: pharmacogenomics, direct-to-consumer testing

\section{Introduction}

Pharmacogenomics has identified many well-known drug-gene interactions that are important for the safety and efficacy of medications. ${ }^{1,2}$ As a result, pharmacogenomic information is increasingly being incorporated into drug labeling. In 2016, 75 drug labels described pharmacogenomics related to drug metabolism and another 25 labels included information about intrinsic metabolic deficiencies, such as glucose6-phosphate dehydrogenase deficiency. A large proportion of the drug-gene pairs were considered actionable; however, with a few exceptions, drug labeling provides no recommendations for genetic testing when it is not compulsory for prescribing. ${ }^{3}$ Although there is actionable drug labeling and pharmacogenomic guidelines, pharmacogenomic testing has not been widely adopted in the clinical setting. Barriers to implementation of testing range from questions about the clinical utility of the test, to convenient access, and insurance coverage. ${ }^{4}$ Over the last several years, genetic testing has become increasingly marketed directly to consumers. This has enabled people to order genetic tests, including pharmacogenomics tests, without involving a health care provider, which could improve access to such testing but raises concerns about potential misinterpretation as well as limiting access to those with resources to pay for testing.

The purpose of this review is to update prior published reviews ${ }^{5-8}$ and to describe the current landscape of the availability of direct-to-consumer marketing of pharmacogenomic tests and how these tests are provided to consumers.

\section{Methods}

Two sources of information were used to identify direct-to-consumer genetic tests: scientific literature and gray literature. PubMed searches were conducted from 2012 to February 28, 2017 for scientific literature related to direct-to-consumer genetic 
testing. Articles were restricted to those published in English and were limited to the last 5 years based on the coverage of prior reviews. ${ }^{5-8}$ Search terms included "direct-to-consumer" AND "genetic" or "genomic" AND "personal genomics". A total of 55 articles were identified. Of those, articles related to direct-to-consumer ancestry testing were excluded, yielding a final sample of 54 articles. To search the gray literature, Google searches were performed between October 26, 2016 and February 28, 2017 to identify currently marketed direct-to-consumer genetic tests. Search terms included "direct-to-consumer genetic" or "genomic testing", and combinations of "genetic", "genomic", or "DNA testing" with "home". This search yielded millions of documents, including websites offering genetic testing services, news articles, scientific literature, and government websites. The first 5 pages of the web searches, containing $\sim 70$ documents, were reviewed.

Genetic tests using a similar strategy as Goddard and colleagues were classified as direct-to-consumer, but with a focus on pharmacogenomic testing. ${ }^{6}$ Genetic tests were designated as direct-to-consumer if they were available for purchase without the involvement of a physician. This was determined by reviewing the test's website. In instances where the website lacked information about the test offered, companies were contacted by telephone or via live web chat in February 2017. Company representatives were asked about the inclusion of pharmacogenetic and cancer-related genes on the test, the availability of genetic counselors, samples test results, and the appropriate ordering procedure (i.e., directly or through a physician). If a representative could not be reached directly, an email was sent to the company and/or a voicemail was left requesting the above information.

\section{Available direct-to-consumer pharmacogenomic tests}

Through review of the scientific and gray literature, 12 companies were identified that previously offered direct-toconsumer pharmacogenomic testing. ${ }^{5,69}$ However, only one - 23andMe (Table 1) - currently offers direct-to-consumer testing. Of the remaining 11,7 of the companies no longer offer testing. Three companies - Genelex, Pathway Genomics, and Veritas - now require a physician to order the tests. Genos, which offers whole-exome sequencing but does not interpret the results, allows the consumer to order the test, the test is then authorized by a physician.

\section{FDA involvement in direct-to- consumer pharmacogenomic tests}

When direct-to-consumer pharmacogenomic tests were first marketed, they appeared to be a novel way to engage patients and increase the availability of pharmacogenomic test results in the medical record. Results from the Impact of Personal Genomics (PGen) Study, which recruited patients who had received direct-to-consumer testing through 23andMe or Pathway Genomics, showed that $91 \%$ of patients received an atypical drug metabolism result and $20 \%$ of patients discussed their genetic results with their primary care provider.,10 However, direct-to-consumer testing has been marred with controversy. Concerns of test validity and quality, misinterpretation of results, and the potential for inappropriate medical decisions and health care services dampened enthusiasm. ${ }^{6,9,11}$ In addition, pharmacogenomic testing is highly complicated. The prevalence of defective alleles is ethnicity-dependent, and inclusion of specific alleles in pharmacogenomic tests differs by company. Therefore, depending on the comprehensiveness

Table I Twelve companies that offered direct-to-consumer pharmacogenomic testing

\begin{tabular}{llll}
\hline Company & Currently direct-to-consumer & Available only with a physician order & $\begin{array}{l}\text { Currently providing } \\
\text { pharmacogenomic testing }\end{array}$ \\
\hline 23andMe & Yes & N/A & Yes \\
DNA Direct & No & No & No \\
Gene Planet & No & No & No \\
Genelex & No & Yes & Yes \\
Genos & No & Yes & Yes* \\
Kimball Genetics & No & No & No \\
Matrix Genomics & No & No & No \\
Navigenics & No & No & No \\
Pathway Genomics & No & Yes & Yes \\
PGx Health & No & No & No \\
Signature Genetics & No & No & No \\
Veritas MyGenome & No & Yes & Yes \\
\hline
\end{tabular}

Note: *Whole-exome sequencing without result interpretation. Abbreviation: N/A, not applicable. 
of the test, the clinical validity and utility of the test may vary by ethnic group. Undetected gene duplications further complicate the interpretation of pharmacogenomic testing. ${ }^{5}$

In 2010, the Food and Drug Administration (FDA) sent letters to several prominent direct-to-consumer genetic testing companies indicating that the tests were medical devices and as such require proper FDA oversight. ${ }^{12}$ These letters had a dramatic effect on the landscape of direct-to-consumer pharmacogenomic testing, such as the disappearance of some companies that were marketing genetic tests and changes in whether companies required the ordering of tests by health care providers. The benefits of provider involvement in ordering genetic tests include ensuring that the appropriate test is ordered, results are recorded in the medical record to appropriately guide clinical management, and aiding in the interpretation of results for the patient/consumer. However, requiring health care provider involvement potentially reduces access to information by requiring additional steps, such as appointments with a health care provider to order the test and follow-up for test interpretation. It also does little to remove the barriers to pharmacogenomic implementation in the clinic. In addition, the results from the PGen Study indicated that $<1 \%$ of participants reported a change in prescription medication without consulting a health care provider. ${ }^{9}$ Thus, the concerns of self-management without health care provider involvement may be unfounded.

In 2013, FDA issued a warning letter to a prominent genetic testing company, 23andMe, Inc., to cease marketing of their tests until receiving proper authorization from the FDA. ${ }^{13,14}$ The warning letter noted concerns about not just disease susceptibility testing, but also the disclosure of pharmacogenomic testing and the potential for consumers to abandon therapy or self-manage dose adjustments based on results. ${ }^{9,14}$ Following the warning letter, 23andMe applied to market a carrier test for Bloom syndrome, and in 2015 the FDA granted authorization for the test. ${ }^{15,16}$ 23andMe expanded to include carrier status for Canavan Disease, Cystic Fibrosis, and other genetic diseases. ${ }^{17}$ With these changes, 23 andMe was no longer conducting any pharmacogenomic testing. However, in April 2017, the FDA allowed marketing of 23 andMe Personal Genome Service Genetic Health Risk (GHR) test, which includes genetic predisposition information for 10 diseases, including glucose-6-phosphate dehydrogenase deficiency, a condition that can be exacerbated by certain drugs.

\section{Future of direct-to-consumer pharmacogenomic testing}

As companies shift away from offering direct-to-consumer pharmacogenomic testing, is there a model that still allows for both patient autonomy and physician oversight? Given the early excitement and the number of people who ordered direct-to-consumer testing during its inception, it is clear that patients want this type of information and do share it with their health care providers. ${ }^{9}$ A recent prospective study of pharmacogenomics results delivered via a clinical decision support (CDS) tool showed that physicians used pharmacogenomic information to alter their prescribing, particularly for those drug-gene interactions with the highest risk. At enrollment in the study, patients were genotyped with a broad pharmacogenomic panel and genotyping results were included in a Genomic Prescribing System to which the physicians had access. The preemptive genotyping removed the testing responsibility from the physicians and provided them with pertinent information for medication prescribing, thus removing some of the barriers to implementation, including availability and access to genetic testing. ${ }^{2}$ This could be replicated in a modern direct-to-consumer model by allowing patients to order a test and then have it approved by a physician. This would address some of the concerns of opponents to direct-to-consumer testing because it would keep the health care provider involved while also empowering patients to make testing decisions. In addition, most pharmacogenomic guidelines provide recommendations for how to use the test results, but do not include guidance on which patients to test. ${ }^{3,18}$

There are caveats to this model. Patients and health care providers should be confident that the tests are clinically valid and laboratories conducting the tests have appropriate sample-handling practices. In addition, the results of the tests need to be interpreted correctly, shared with the health care provider and pharmacists, and incorporated into the medical record in a manner that is usable and easy to comprehend. This would require a high level of physician interest and engagement in pharmacogenomic testing and a willingness to translate testing results into the electronic medical record which is appropriately shared. Successful implementation of this model requires buy in from patients, genetic counselors, physicians, laboratories, and insurers.

\section{Conclusion}

The landscape of availability of direct-to-consumer genetic testing has changed with decreasing availability to testing in the absence of a physician order. However, with the recent approval of 23 andMe to once again offer disease-based susceptibility testing directly to consumers, there may be a future resurgence in the availability of direct-to-consumer pharmacogenomics tests. Hybrid models may be developed 
to increase accessibility and use of pharmacogenomics tests, which could lead to the avoidance of high-risk prescriptions and a reduction in the risk of serious adverse events.

\section{Disclosure}

The authors report no conflicts of interest in this work.

\section{References}

1. Relling MV, Evans WE. Pharmacogenomics in the clinic. Nature. 2015;526(7573):343-350.

2. O’Donnell PH, Wadhwa N, Danahey K, et al. Pharmacogenomicsbased point-of-care clinical decision support significantly alters drug prescribing. Clin Pharmacol Ther. Epub 2017 Apr 11.

3. Filipski KK, Pacanowski MA, Ramamoorthy A, Feero WG, Freedman AN. Dosing recommendations for pharmacogenetic interactions related to drug metabolism. Pharmacogenet Genom. 2016;26(7): 334-339.

4. Stanek EJ, Sanders CL, Taber KA, et al. Adoption of pharmacogenomic testing by US physicians: results of a nationwide survey. Clin Pharmacol Ther. 2012;91(3):450-458.

5. Chua EW, Kennedy MA. Current state and future prospects of directto-consumer pharmacogenetics. Front Pharmacol. 2012;3:152.

6. Goddard KA, Robitaille J, Dowling NF, et al. Health-related directto-consumer genetic tests: a public health assessment and analysis of practices related to Internet-based tests for risk of thrombosis. Public Health Genomics. 2009;12(2):92-104.

7. Covolo L, Rubinelli S, Ceretti E, Gelatti U. Internet-based direct-toconsumer genetic testing: a systematic review. $J$ Med Internet Res. 2015;17(12):e279.
8. Roberts JS, Ostergren J. Direct-to-consumer genetic testing and personal genomics services: a Review of recent empirical studies. Curr Genet Med Rep. 2013;1(3):182-200.

9. Carere DA, VanderWeele TJ, Vassy JL, et al. Prescription medication changes following direct-to-consumer personal genomic testing: findings from the Impact of Personal Genomics (PGen) Study. Genet Med. 2017;19(5):537-545.

10. van der Wouden CH, Carere DA, Maitland-van der Zee AH, Ruffin MT 4th, Roberts JS, Green RC; Impact of Personal Genomics Study Group. Consumer perceptions of interactions with primary care providers after direct-to-consumer personal genomic testing. Ann Intern Med. 2016;164(8):513-522.

11. McGrath SP, Coleman J, Najjar L, Fruhling A, Bastola DR. Comprehension and data-sharing behavior of direct-to-consumer genetic test customers. Public Health Genomics. 2016;19(2):116-124.

12. US Food and Drug Administration. Letters to Industry; 2010. Available from: https://www.fda.gov/MedicalDevices/ResourcesforYou/Industry/ ucm111104.htm. Accessed June 21, 2017.

13. Yim SH, Chung YJ. Reflections on the US FDA's warning on direct-toconsumer genetic testing. Genomics Inform. 2014;12(4):151-155.

14. US Food and Drug Administration. 23andMe, Inc; 2013. Available from: https://www.fda.gov/ICECI/EnforcementActions/WarningLetters/2013/ ucm376296.htm. Accessed March 1, 2017.

15. US Food and Drug Administration. FDA permits marketing of first direct-to-consumer genetic carrier test for Bloom syndrome [press release]. 2015.

16. Lutins E, Terry SF. Will the wall come tumbling down?. Genet Test Mol Biomarkers. 2015;19(5):226-227.

17. 23andMe. https://www.23andme.com/. Accessed April 13, 2017.

18. Relling MV, Klein TE. CPIC: Clinical Pharmacogenetics Implementation Consortium of the Pharmacogenomics Research Network. Clin Pharmacol Ther. 2011;89(3):464-467.
Pharmacogenomics and Personalized Medicine

\section{Publish your work in this journal}

Pharmacogenomics and Personalized Medicine is an international, peerreviewed, open access journal characterizing the influence of genotype on pharmacology leading to the development of personalized treatment programs and individualized drug selection for improved safety, efficacy and sustainability. This journal is indexed on the American Chemical
Dovepress

Society's Chemical Abstracts Service (CAS). The manuscript management system is completely online and includes a very quick and fair peer-review system, which is all easy to use. Visit http://www.dovepress. com/testimonials.php to read real quotes from published authors. 